\title{
ELECTROCHEMICAL BEHAVIOR OF PARENT AND PHOTODEGRADATION PRODUCTS OF SOME SELECTED PESTICIDES
}

\author{
Carlos M. P. Vaz", Paulo R. V. Silva Jr. e Isis Prado \\ Embrapa Instrumentação Agropecuária, CP 741, 13560-970 São Carlos - SP, Brasil \\ Giuliane M. Castanho \\ Centro de Energia Nuclear na Agricultura, Universidade de São Paulo, CP 96, 13400-970 Piracicaba - SP, Brasil \\ Fabio R. Simões \\ Departamento de Química, Universidade Federal de São Carlos, CP 676, 13560-970 São Carlos - SP, Brasil \\ Sérgio A. S. Machado \\ Instituto de Química de São Carlos, Universidade de São Paulo, CP 780, 13560-970 São Carlos - SP, Brasil
}

Recebido em 9/4/07; aceito em 15/2/08; publicado na web 31/7/08

\begin{abstract}
Electrochemical behavior of pesticides is extensively studied, but little attention has been given to the study of their degradation products (by-products) by electrochemical methods. However, the degradation products of pesticides can be even more toxic then the parent products and such studies should be encouraged. Therefore, the objective of this work was to evaluate the electroactivity of by-products of imazaquin, methylparathion, bentazon and atrazine, generated by UV irradiation and measured using cyclic and differential pulse voltammetry and UV-visible absorption spectrophotometry. Results have shown that several by-products exhibit electroactivity, allowing, in some cases, the simultaneous determination of both parent and degradation products.
\end{abstract}

Keywords: pesticides; differential pulse voltammetry; photodegradation.

\section{INTRODUCTION}

Electroanalytical techniques has been shown to be very useful in the study of toxic substances such pesticides used for disease and pest control, mainly related to environmental concerns as the contamination of water,,$^{1-4}$ soil $^{5-7}$ resources and food supplies. ${ }^{8}$ There are a significant number of electrochemical studies and electroanalytical methods for the determination and evaluation of pesticides. However, due to the great number of active ingredients of pesticides available in the market and new products every year there are still a great demand for such studies, including direct methods of analysis with conventional electrodes of $\mathrm{Hg},{ }^{5,9}$ carbon, ${ }^{1,10,11} \mathrm{Pt}, \mathrm{Au}^{13,14}$ or modified ones ${ }^{15-17}$. Moreover, most of the electroanalytical studies of pesticides are focused on the analysis of the parent substances and on the identification of products formed on the electrode surface by the electrochemical reaction. There are few information about the electroactivity of degradation products of pesticides generated by chemical, photochemical and biological processes, that in some circumstances can be even more toxic and dangerous than the parent products.

From the electroanalytical point of view the presence of electroactive by-products can interfere in the determination of the parent pesticide if the redox potentials are close or it can be an advantage if both electroactives compounds (parent and by-products) present very different redox potentials, allowing the determination of such compounds simultaneously.

Photodegradation products of the triazinone herbicide metamitron and the chloro-nicotynil insecticide imidacloprid are electroactives ${ }^{18}$ in hanging mercury electrode and their photochemical degradation pathways were elucidate using differential pulse polarography (DPP) and micellar electrokinetic chromatography.

The electrochemical behavior of the organophosphate insecticide methylparathion under UV irradiation were investigated in aqueous

\footnotetext{
*e-mail: vaz@cnpdia.embrapa.br
}

medium ( $\mathrm{pH}$ 6.5) with DPP at two different wavelength and in the presence of atmospheric oxygen and $\mathrm{TiO}_{2} \cdot{ }^{19}$ Two major electroactive photodegradation products were observed. Combined spectroscopic and electrochemical experiments suggested the presence of p-nitrobenzoic acid as a common electroactive product. In both studies ${ }^{18,19}$ the DPP technique showed to be very effective in the identification of the parent and the major photochemical degradation products of the pesticides.

The electroactivity of the herbicide atrazine and its degradation products under UV irradiation were studied ${ }^{4}$ also by DPP. The two cathodic peaks observed for atrazine were attributed to the reduction of protonated species on mercury electrode. Hydroxiatrazine, the main photochemical and chemical degradation product of atrazine was not electroactive and therefore does not interfere in the electroanalytical determination of the parent compound.

Some other studies have shown the ability of electrochemical methods to identity and quantify the parent and the degradation products of pesticides. A degradation product of the herbicide propanil, ${ }^{11}$ 3-4-dichloroaniline (DCA), generated by enzymatic or chemical hydrolysis or photolysis, presented an oxidation peak at $+0.66 \mathrm{~V}$, allowing its determination in the presence of propanil which has an oxidation peak at $+1.27 \mathrm{~V}$, with no peak overlapping. Electrochemical behavior of desethyl atrazine and desethyl terbutylazine, the desethylated degradation products of atrazine and terbutylazine were evaluated by polarography, ${ }^{20}$ showing different $\mathrm{pH}$ dependences in their reduction processes.

The electrochemical behavior of two hydrolysis products of the herbicide oxadiazon was studied by cyclic and square-wave voltammetry using a glassy carbon electrode. ${ }^{21}$ Based on the electrochemical reduction of a degradation product of oxadiazon a simple electroanalytical procedure was developed for the determination of oxadiazon in a commercial formulation of the herbicide.

Based on the ample literature about electrochemistry of pesticides and the few examples showed above, it can be considered that the great 
development and advances of the electrochemistry and electroanalysis of organic pesticides obtained in the last decades was not followed by studies of their by-products or degradation products of the parent pesticides and such studies should be increased in the next years.

In the present work it is evaluated the electroactivity of the parent and photolysis products of the imazaquin, methylparathion, bentazon and atrazine and their possible interference on the determination of their parent compounds. Pesticides were irradiated with an ultraviolet lamp and analyzed by cyclic voltammetry, differential pulse polarography or voltammetry and UV-visible absorption spectrophotometry as a function of time. The work has also the objective of encourage more studies on the electrochemistry and electroanalysis of byproducts of pesticides that are rare in the literature, as pointed out.

\section{EXPERIMENTAL}

Samples of the pesticides were prepared and analyzed before and after UV irradiation by cyclic voltammetry and DPP, according to the information presented in Table 1.

The electroanalytical parameters were selected based on previous studies. 4,6,22,23 The methylparathion, imazaquin and atrazine present reduction reactions at the mercury electrode with best analytical responses at $\mathrm{pH} 6.5,3.0$ and 2.3, respectively. Bentazon is electroactive on glassy carbon electrode in acidic medium, but the complex oxidation mechanism causes severe adsorption problems and consequent poisoning of the electrode surface. Therefore, a carbon paste electrode, which allows easy surface renew, was used for the bentazon determination.

Electrochemical measurements (cyclic voltammetry and differential pulse porarography/ voltammetry) were carried out in a trace analyzer model 293 from EG\&G for the mercury electrode (model 303A from $\mathrm{EG} \& \mathrm{G}$ as working electrode, $\mathrm{Ag} / \mathrm{AgCl}$ as reference and platinum as auxiliary electrode) measurements for imazaquin, methylparathion and atrazine and in a potenciostat-galvanostat model 283 from EG\&G for the measurements with the carbon paste as working electrode (saturated calomel electrode-SCE as reference and platinum as auxiliary electrode) for bentazon determination. UV-visible spectra were obtained on a Shimadzu model UV-1601 PC with quartz cubes.

The pesticides solutions samples $(20 \mathrm{~mL})$ were irradiated with an ultraviolet lamp $(500 \mathrm{~W})$ at different period of times for each pesticide, according to their specific degradation velocities, and aliquots of $7 \mathrm{~mL}$ (for polarography/imazaquin-methylparathion-atrazine) or $20 \mathrm{~mL}$ (for voltammetry/bentazon) were periodically took from the recipient and first analyzed by the electrochemical techniques and after that the same aliquot were transferred to $3 \mathrm{~mL}$ quartz cube and analyzed by UV-visible spectrophotometry. Just one scan was performed for both voltammetric and spectrophotometric techniques at each irradiation time. Recovered solutions from both measurements (electrochemical and UV-visible) were returned to the irradiation recipient for continuing the irradiation process until close to total degradation of the parent pesticide.

Carbon paste electrode was made of a graphite powder-Nujol ${ }^{\mathrm{TM}}$ mixture in a proportion of 75:25. Graphite powder was obtained from Fisher and the mineral oil (Nujol) from Schering-Plough and the gra- phite powder was used as received. Carbon paste was placed in $1 \mathrm{~mL}$ hypodermic syringes (insulin injection type) with a copper wire for the external electrical contact. After each measurement the surface electrode was renewed by carefully passing its surface on a clean paper sheet.

All chemicals used were of P.A. grade except the pesticides, which analytical standard purities are presented in Table 1. Electrolyte used was $\mathrm{CaCl}_{2} 0.01 \mathrm{~mol} \mathrm{~L}^{-1}$ and the pesticides $\mathrm{pH}$ solutions were adjusted when necessary with $\mathrm{HCl}$.

\section{RESULTS AND DISCUSSION}

Cyclic voltammograms of the pesticides before and after UV irradiation are presented in Figure 1. Imazaquin present two well defined reduction peaks at $\mathrm{pH} 3.0(-0.42$ and $-0.96 \mathrm{~V})$, which are significantly reduced after $30 \mathrm{~min}$ of irradiation and two new reduction peaks appear at different potentials indicating the electroactivity of the degradation products (Figure 1a). Atrazine, which is significantly degraded after $30 \mathrm{~min}$ of irradiation, presents a reduction peak at $-1.0 \mathrm{~V}$, but no electroactive degradation product (Figure 1c). The methylparathion presents a reduction peak at $-0.5 \mathrm{~V}(\mathrm{pH} 6.5)$ and much higher stability to photolysis than atrazine, imazaquin and bentazon (Figure 1b). A small reduction peak can be detected at $-0.7 \mathrm{~V}$, which can be associated to a degradation product of the parent compound. Bentazon showed an oxidation peak at $+0.95 \mathrm{~V}(\mathrm{pH} 3.4)$ and no electroactive degradation product (Figure 1d).
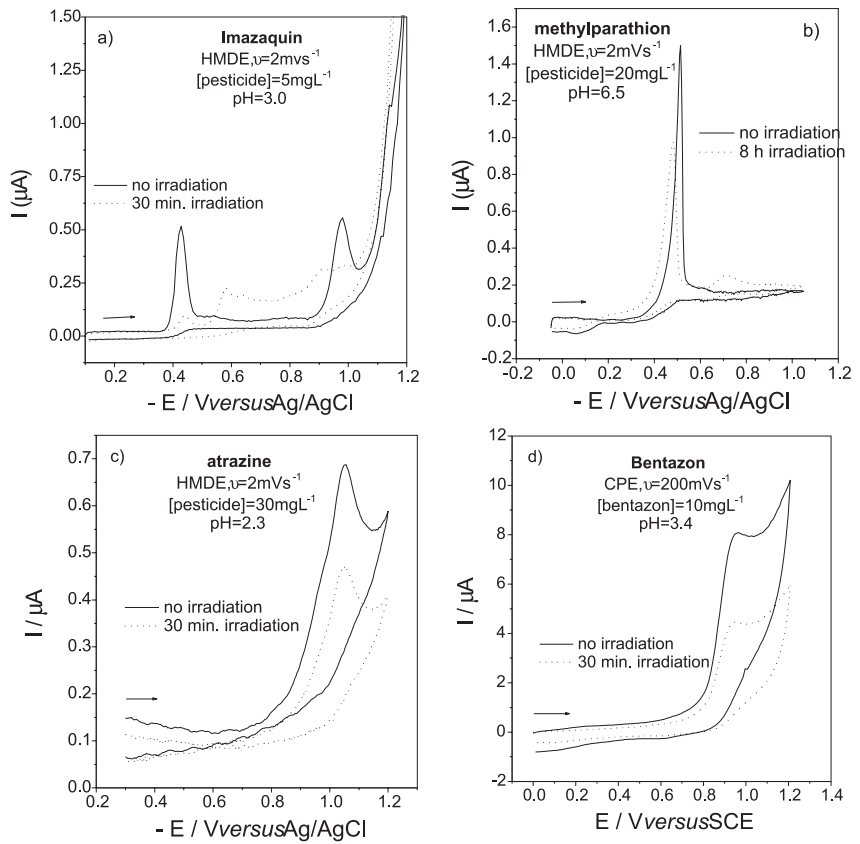

Figure 1. Cyclic voltammograms of pesticides imazaquin, methylparathion and atrazine with a mercury electrode and bentazon with a carbon paste electrode before and after $U V$ irradiation. Electrolyte is $\mathrm{CaCl}_{2} 0.01 \mathrm{~mol} \mathrm{~L}^{-1}$ and $\mathrm{pH}$ were adjusted when necessary with $\mathrm{HCl}$

Table 1. Some parameters of the pesticides and the experimental conditions for the electrochemical and spectrophotometric measurements

\begin{tabular}{lcccccc}
\hline Pesticide & $\mathrm{C}_{\mathrm{i}}\left(\mathrm{mg} \mathrm{L}^{-1}\right)$ & Pesticide Purity $(\%)$ & $\mathrm{pH}$ & Electrode & $v\left(\mathrm{mVs}^{-1}\right)$ & scan potentials / V (cyclic voltammetry) \\
\hline imazaquin & 5 & 97.0 & 3.0 & HMDE & 2 & -0.10 to -1.20 \\
methylparathion & 20 & 80.7 & 6.5 & HMDE & 2 & +0.05 to -1.17 \\
bentazon & 10 & 99.8 & 3.4 & CPE & 200 & -0.30 to -1.20 \\
atrazine & 30 & 99.0 & 2.3 & HMDE & 2 & 0 to -1.20 \\
\hline
\end{tabular}

$\mathrm{C}_{\mathrm{i}}$ : initial concentration of irradiated pesticides samples 
Differential pulse polarograms or voltammograms and absorption spectra of the pesticides before and after UV irradiation in $\mathrm{pH} 3.0$, 6.5, 2.3 and 3.4 are shown in Figures 2, 34 and 5 for imazaquin, methylpararthion, atrazine and bentazon, respectively.

Differential pulse polarograms of imazaquin present three reduction peaks (in the cyclic voltammograms two well defined peaks appeared) that decrease with the irradiation time. At least four new reduction peaks appear in the differential pulse polarograms of the irradiated solutions. According to a previous work, ${ }^{24}$ which studies the phototransformation of imazaquin in aqueous solution, four degradation products were identified by HPLC-UV and HPLC-MS. These products were proposed to be 2,3-pyridinecarboxylic acid, 7-hydroxyfuro[3,4-b]pyridine-5(7H)one, 3-qinolinecarboxylic acid and a non-identified photoproduct. On the other hand the UV-visible spectra of imazaquin showed that the spectrophotometric technique was able to identify only the degradation process of the parent compound.

The main environmental degradation by-products of methylparathion are the methylparaoxon and p-nitrophenol. ${ }^{25}$ Figure 3 presents the differential pulse polarograms and UV-visible spectra of methylparathion at different irradiation times.

CG-MS spectroscopic and voltammetric data from literature concerning the irradiation of methylparathion in the presence of atmospheric oxygen or nitrogen and metallic $\mathrm{TiO}_{2}$ suggested the formation of p-nitrobenzoic acid as a major decomposition product. ${ }^{19}$ In voltammograms of Figure $3 \mathrm{a}$ this product is probably associated with the less cathodic peak at $-0.18 \mathrm{~V}$ that appeared only after $48 \mathrm{~h}$ of irradiation. The more cathodic peak at -0.68 was also previously reported, but was not properly identified. ${ }^{19}$ Since methylparathion contains a nitro group and sulfur and phosphorous atoms, $\mathrm{NO}_{2}^{-}, \mathrm{NO}_{3}{ }^{-} \mathrm{PO}_{3}^{-}, \mathrm{PO}_{3}{ }^{4-}$ and $\mathrm{SO}_{4}{ }_{4}^{2-}$ are potential ionic degradation by-products. ${ }^{26}$ After $8 \mathrm{~h}$ of irradiation the reduction peak of methylparathion $(-0.5 \mathrm{~V})$ are displaced to less negative potentials, indicating an electrocatalytical process or transformation to other by-product. The very complex voltammetric behavior observed for methylparathion after several hours of irradiation indicates the necessity of additional electrochemical studies of such process. UV-visible spectra of methylparathion (Figure $3 \mathrm{~b}$ ) shows maxima at $275 \mathrm{~nm}$ and a displacement to higher wavelengths and formation of new overlapped bands at 325 and $400 \mathrm{~nm}$ that can be attributed to the p-nitrophenol absorption bands. ${ }^{27}$

Photolysis of atrazine produces hydroxiatrazine, de-ethyl-atrazine, de-isopropyl-atrazine as intermediate species, although concentrations of the two last are extremely low, compared to hydroxiatrazine. ${ }^{28}$ Figure 4 shows differential pulse polarograms and UV-visible spectra of irradiated atrazine at different irradiation times.

As can be seen, hydroxiatrazine is not electroactive. De-ethylatrazine has been shown to be electroactive, ${ }^{20}$ but its reduction potential is too close to atrazine and can not be separated from the reduction peak of atrazine in a differential pulse polarogram. However, as production of the de-ethyl-atrazine and de-isopropyl-atrazine is very low in the photolysis process, the reduction peak observed in Figure 4a can be basically attributed to atrazine. On the other hand UV-visible spectra shows the atrazine and hydroxiatrazine maxima at $223 \mathrm{~nm}$ and $250 \mathrm{~nm}$ respectively (Figure 4b), allowing the determination of both species by the absorption spectrophotometry in the UV-visible technique.

Differential pulse voltammograms and UV-visible spectra of irradiated bentazon are presented in Figure 5a and 5b, respectively.

Although a slight decrease of the oxidation peak and adsorption bands of bentazon have been observed as a function of time, compared to atrazine and imazaquin, no new peak or band have appeared after some hours of irradiation. A previous study ${ }^{29}$ showed that bentazon in its dissociated form ( $\mathrm{pH} 2$ adjusted with sulfuric acid) presented a photolysis half-life of $11 \mathrm{~h}$ and in pH 6.8 its half-life was $2 \mathrm{~h} 45$
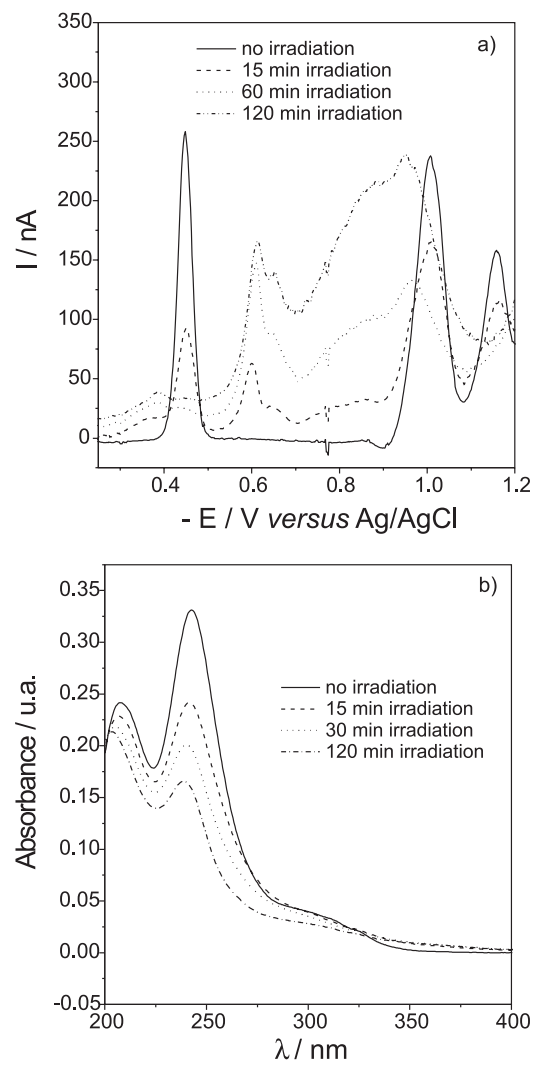

Figure 2. Differential pulse polarograms of imazaquin $\left(5 \mathrm{mg} \mathrm{L}^{-1}\right)$ in $\mathrm{CaCl}_{2}$ $0.01 \mathrm{~mol} \mathrm{~L}^{-1}, \mathrm{HMDE}, \mathrm{v}=2 \mathrm{mVs}^{-1}$ (a) and absorbance spectra (b). $\mathrm{pH}=3.0$ adjusted with $\mathrm{HCl}$
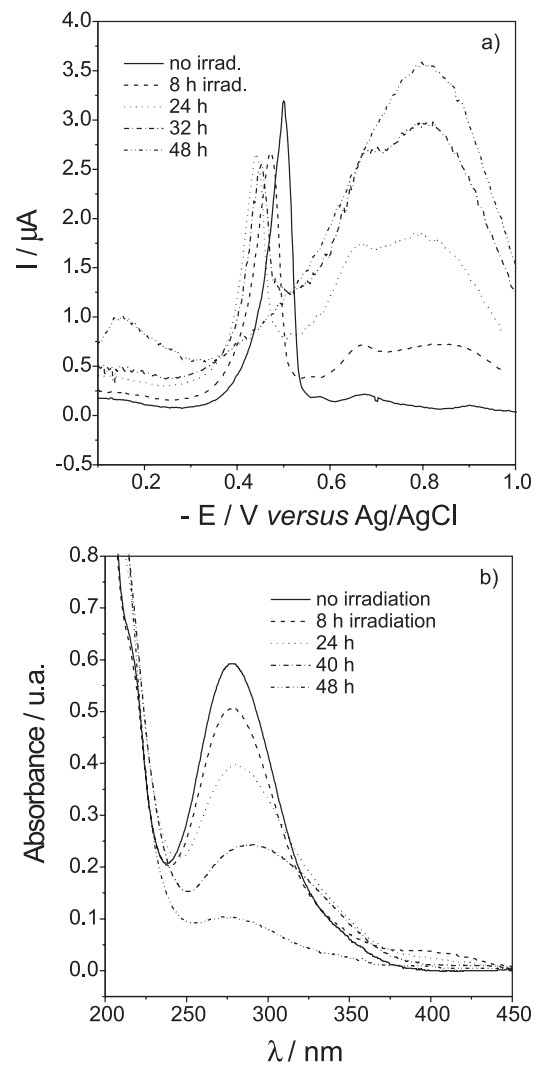

Figure 3. Differential pulse polarograms of methylparathion $\left(20 \mathrm{mg} \mathrm{L}^{-1}\right)$ in $\mathrm{CaCl}_{2} 0.01 \mathrm{~mol} \mathrm{~L}^{-1}, \mathrm{HMDE}, \mathrm{v}=2 \mathrm{~m} \mathrm{Vs}^{-1}$ (a) and absorbance spectra (b). $p H=6.5$ 

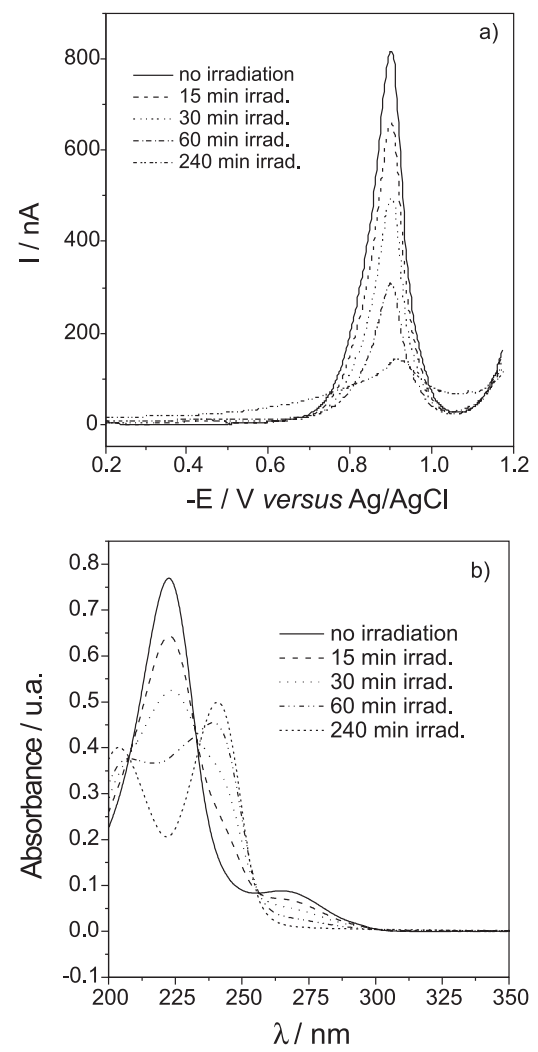

Figure 4. Differential pulse polarograms of atrazine $\left(30 \mathrm{mg} \mathrm{L}^{-1}\right)$ in $\mathrm{CaCl}$ $0.01 \mathrm{~mol} \mathrm{~L}^{-1}, H M D E, v=2 \mathrm{mVs}^{-1}(a)$ and absorbance spectra (b). $\mathrm{pH}=2.3$ adjusted with $\mathrm{HCl}$
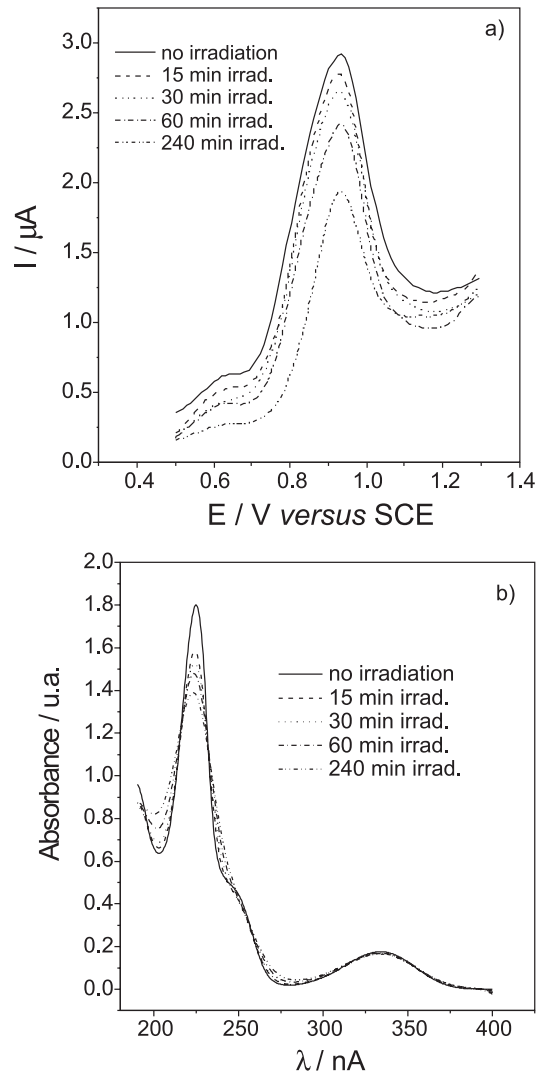

Figure 5. Differential pulse voltammograms of bentazon $\left(10 \mathrm{mg} \mathrm{L}^{-1}\right)$ in $\mathrm{CaCl}_{2}$ $0.01 \mathrm{~mol} \mathrm{~L}^{-1}, C P E, \mathrm{v}=200 \mathrm{~m} \mathrm{Vs}^{-1}($ a) and absorbance spectra (b). $\mathrm{pH}=3.4$ adjusted with $\mathrm{HCl}$
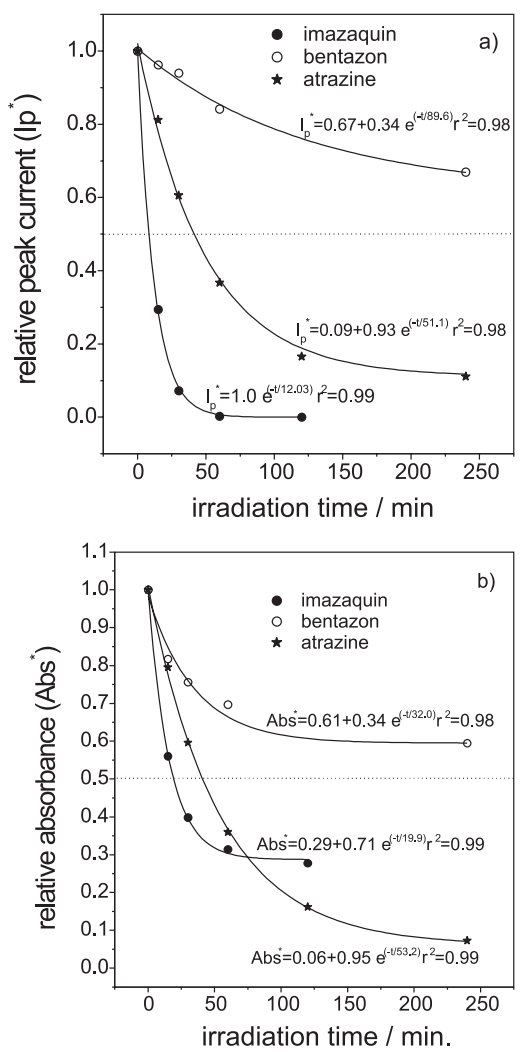

Figure 6. Relative peak current (a) and absorbance (b) obtained from Figures 2, 4 and 5 for imazaquin, atrazine and bentazon, respectively. I $p^{*}=\operatorname{Ip} / \mathrm{I} p($ at $t=0)$ and $A b s^{*}=A b s / A b s(a t t=0)$. Solid lines are regression curves obtained by first order exponential decay equation fittings

min. Figure $6 \mathrm{a}$ and $6 \mathrm{~b}$ present the degradation kinetic of bentazon measured by DPV and UV-vis.

The estimated half-life of bentazon at $\mathrm{pH} 3.4$, considering a first order exponential decay equation was around $8 \mathrm{~h}$, agreeing with the previous photolysis kinetic study using chromatographic techniques ${ }^{29}$. Half-life estimated using the data presented in Figure 6 for atrazine $(\mathrm{pH} 2.3)$ and imazaquin (pH 3.0) were around 15 and 40 min, respectively.

\section{CONCLUSIONS}

Analysis of the electroactive behavior of photodegration products of the pesticides imazaquin, methylparathion, atrazine and bentazon provided important information about possible interference or the ability to determine both parent and degradation products of the pesticides by differential pulse voltammetry.

Imazaquin at $\mathrm{pH} 3.0$ presented three reduction peaks and four new reduction peaks associated to the photodegradation products using the hanging mercury electrode. Atrazine ( $\mathrm{pH}$ 2.3) and bentazon ( $\mathrm{pH}$ 3.4) did not present electroactive photolysis by-products using hanging mercury and carbon paste electrodes.

The proposed study using ultraviolet irradiation to produce the degradation products of the pesticides, differential pulse voltammetry and cyclic voltammetry to evaluate their electroactivity and UV-vis. espectrophotometry as a complementary technique is a simple and interesting approach to evaluate electroactivity and interference and should be applied to other pesticides, different $\mathrm{pH}$ and other electrode materials. However, more detailed and specific studies for the exact identification of the pesticides degradation products should also use chromatographic methods and spectroscopic methods as NMR and FTIR. 


\section{ACKNOWLEDGEMENTS}

To FAPESP for providing a MSc fellowship for the second author and EMBRAPA, CAPES (01/13745-7), CNPq (310750/2006-7) and FAPESP for the financial support to the project.

\section{REFERENCES}

1. Codognoto, L.; Tanimoto, S. T.; Pedrosa, V. A; Suffredini, H. B.; Machado, S. A. S.; Avaca, L. A.; Electroanalysis 2006, 18, 253.

2. Perez-Lopez, J. A.; Zapardiel, A.; Bermejo, E.; Arauzo, E.; Hernandez, L.; Fresenius J. Anal. Chem. 1994, 350, 620.

3. Massaroppi, M. R. C.; Machado, S. A. S.; Avaca, L. A.; J. Braz. Chem. Soc. 2003, 14, 113.

4. Vaz, C. M. P.; Crestana, S.; Machado, S. A. S.; Mazo, L. H.; Avaca, L. A.; Int. J. Environ. Anal. Chem. 1996, 62, 65.

5. Santos, L. B. O.; Abate, G.; Masini, J. C.; J. Braz. Chem. Soc. 2006, 17, 36.

6. Castanho, G. M.; Vaz, C. M. P.; Machado, S. A. S.; J. Braz. Chem. Soc. 2003, 14, 594

7. Sreedhar, N. Y.; Reddy, P. R. K.; Reddy, G. R. V. S.; Reddy, S. R. J.; Bull. Chem. Soc. Jpn. 1997, 70, 2425.

8. Galli, A.; Souza, D.; Garbellini, G. S.; Coutinho, C. F. B.; Mazo, L. H.; Avaca, L. A.; Machado, S.A.S.; Quim. Nova. 2006, 29, 105.

9. Barroso, M. F.; Nunes, O. C.; Vaz, M. C.; Delerue-Matos, C.; Anal. Bioanal. Chem. 2005, 381, 879.

10. Manisankar, P.; Vedhi, C.; Selvanathan, G.; Bull. Electrochem. 2004, 20, 81.

11. Garrido, E. M.; Lima, J. L. F. C.; Delerue-Matos, C.; Borges, F. ; Silva, A. M. S.; Brett, A. M. O.; Anal. Chim. Acta 2001, 434, 35.

12. Drevinek, M.; Horak, V.; J. Electroanal. Chem. 1997, 423, 83.
13. Souza, D.; Machado, S. A. S.; Anal. Bioanal. Chem. 2005, 382, 1720.

14. Souza, D.; Machado, S. A. S.; Anal. Chim. Acta 2005, 546, 85.

15. Manisankar, P.; Selvanathan, G.; Vedhi, C.; Talanta 2006, 68, 686.

16. Simões, F. R.; Mattoso, L. H. C.; Vaz, C. M. P.; Sens. Lett. 2004, 2 , 221.

17. Manisankar, P.; Selvanathan, G.; Vedhi, C.; Int. J. Environ. Anal. Chem. 2005, 85, 409.

18. Cacho, J.; Fierro, I.; Deban, L.; Vega, M.; Pardo, R.; Pest. Sci. 1999, 55, 949.

19. Manzanilla-Cano, J. A.; Barcelo-Quintal, M. H.; Reyes-Salas, E. O.; Flores-Rodriguez, J.; Int. J. Environ. Anal. Chem. 2001, 80, 115.

20. Colombini, M. P.; Fuoco, R.; Giannarelli, S.; Pospisil, L.; Trskova, R.; Microchim. J. 1998, 59, 239.

21. Garrido, E. M.; Lima, J. L. F. C.; Delerue-Matos, C.; Borges, M. F. M.; Brett, A. M. O.; Electroanalysis 2001, 13, 199.

22. Moraes, M.; Vaz, C. M. P. ; Machado, S. A. S.; Comumicado Técnico 1997, 19, 7.

23. Garrido, E. M.; Lima, J. L.C.; Delerue-Matos, C. M.; Brett, A. M. O.; Talanta 1998, 46, 1131.

24. Barkni, H.; Catastini, C.; Emmelin, C.; Sarakha, M.; Azzouri, M. E.; Chovelon, J. M.; J. Photochem. Photobiol., A 2005, 170, 27.

25. Kim, T.; Kim, J.; Choi, K.; Stenstrom, M. K.; Zoh, K.; Chemosphere 2006, 62, 926.

26. Konstantinou, I. K.; Albaris, T. A.; Appl. Catal., B 2003, 42, 319.

27. Simões, F. R.; Silva, W. T. L.; Simões, M. L.; Martin-Neto, L.; Vaz, C. M. P.; Int. J. Environ. Anal. Chem. 2006, 86, 779.

28. Bianchi, C. L.; Pirola, C.; Ragaini, V.; Selli, E.; Appl. Catal., B 2006, 64, 151.

29. Chiron, S.; Abian, J.; Ferrer, M.; Sanchez-Baeza, F.; Messeguer, A.; Barcelo, D.; Environ. Toxicol. Chem. 1995, 14, 1287. 